\title{
The Effects of Performing Prayer on the Physical Fitness Levels of Men Over 60 Years Old
}

\author{
Selami Yüksek \\ Correspondence: Selami Yüksek, Karadeniz Teknik University, Turkey.
}

Received: September 10, 2017

Accepted: October 5, $2017 \quad$ Online Published: October 15, 2017

doi:10.11114/jets.v5i11.2641

URL: https://doi.org/10.11114/jets.v5i11.2641

\begin{abstract}
This study was carried out to determine and compare the physical fitness levels of elderly people who pray regularly with those who lead a sedentary lifestyle, as well as to emphasize the importance of performing regular prayer for the physical fitness levels of elderly people.

The research sample consisted of 849 men who were able to conduct their daily activities independently, with no serious health problems, and who were viewed as healthy according to their age category. They were divided on the basis of age into 5 age groups. The Senior Fitness Test (SFT) was applied to determine the physical fitness levels of elderly men (Rikli, Jones, 2001). In addition, a questionnaire was administered to learn whether the subjects performed regular prayer or not.

The differences between the prayer group and sedentary group were analyzed using the Independent Samples Test. It was found that the physical fitness levels of the elderly men who performed prayer were higher than those of the sedentary group; all of the parameters of physical fitness measured through the SFT protocol were higher in the case of the elderly men who performed prayer.
\end{abstract}

Keywords: prayer, physical fitness, aging

\section{Introduction}

Exercise is a sub-group of physical activity which is defined as planned, structured and repetitive; it is aimed to develop and preserve physical fitness, as well as providing many other benefits (Brown, Lee, 2004). With advancing age, a decrease in physical activity is often seen; research has shown a direct correlation between increased inactivity and serious health problems such as cardiovascular disease, osteoporosis and colon cancer (Rajeski, Brawley, 2006).

Performing prayer is the second of the important divine services of Islam, after the kalmia shahadah (serving Allah). It is the obligation of every Muslim woman and man of responsible age and includes a number of prescribed elements (Yllmaz, 2006). Prayer accustoms Muslims to a healthy and whole some lifestyle by dividing time into parts. Ablution with clean water, standing up, bending the knees, kowtowing and saluting also constitute a form of physical exercise for the body (Raci, Lamia, 1997), as prayer consists not only of saying the suras by heart and meditating, but also involves various body movements and positions. Specifically, the body positions included in prayer comprise standing up (rising), bowing (rüku), placing the head on the floor (kowtow) and salute. These movements are repeated everyday in a rhythm as prescribed (Ibrahim, Wam Ahmad, 2008). To date, there have been no studies concerning the energy-dissipating value of performing prayer. However, the movements and positions involved are often compared with Yoga and Tai-Chi, which provide the equivalent of approximately 4 METs of exercise (Maughan, 2000), or 4 calories in 1 hour per kilo of body weight (e.g., for a person of $70 \mathrm{kilos} ; 70 \mathrm{x} 4=280 \mathrm{cal} /$ hour). Performing prayer is thought to have a similar effect.

Therefore, as a means to create a better understanding of the physical benefits of Muslim prayer, this study was carried out to determine and compare the physical fitness levels of elderly people who perform prayer versus those who maintain a sedentary lifestyle, and to examine the effects of performing prayer on the physical fitness levels of elderly people.

\section{Material and Method}

\subsection{Participants}

This study was carried out with the voluntary participation of 932 men aged 60 years or more who were able to independently conduct their normal daily activities and who did not have any serious health problems. All participants 
provided written consent in accordance with the declaration of 1964 Helsinki, after reading the verbal and written explanations of the potential risks of the study. The participants were informed about the procedure of the experiment and were told that at any given time they could voluntarily withdraw from the experiment. Certain demographic information was obtained about the participants via a questionnaire, including whether they perform prayer regularly; if they do perform prayer regularly, how they perform it (e.g., sitting on a chair or standing up according to the standard practice); and how long have they been performing prayer regularly. Subjects who indicated that they do not perform prayer regularly, perform it seated, or do not perform prayer at all, were included in the "non-prayer performing" (sedentary) category, as those who perform prayer sitting on a chair are not applying the requisite physical movements. Subjects who indicated that they perform prayer regularly (5 times a day-40-rakat) were was included in the "prayer-performing" category. Subjects who had orthopedic or mental disabilities or neurologic or advanced cardiovascular chronic illnesses that might impair or limit test protocols were not included in the study. In performing the physical fitness tests, any clothing that could impede or limit movements, or items like jackets, coats were removed. In order for each subject to proceed through the fitness stations efficiently, an experienced assistant was employed for each station. Any subjects who were unable to complete any of the stations included in the test protocol were excluded from the evaluation.

Distribution of the participants after eliminating those not qualified. The distribution of the 849 participants who were found to be suitable for the test criteria and successfully completed the tests are as follows, according to their age range and whether they performed prayer or not: age 60- 64 (97 performing prayer - 106 not performing prayer); age 65 - 69 (155 performing prayer - 123 not performing prayer); age $70-74$ (121 performing prayer - 98 not performing prayer); and age 75-79 (60 performing prayer -47 not performing prayer). A total of 461 participants were included in the "prayer-performing" group, with 388 in the "non-prayer performing" group.

\subsection{Materials}

The materials used in the study included the following: a flat-back chair without arm rests, with a $43.18 \mathrm{~cm}$ sitting height; a specially made $3.63 \mathrm{~kg}$ dumbbell a 2.44 -meter funnel; a $50-\mathrm{cm}$ long wooden ruler; $1.5 \mathrm{x} 1.5 \mathrm{~m}$ mats for the step station; a stopwatch; and a bascule and tension meter (Rikli, Jones, 2001). Each participant completed a two-minute step test barefoot on one of the $1.5 \times 1.5 \mathrm{~m}$ mats. The same devices were used for each participant's physical and physiological measurements.

\subsection{Measurements}

The body mass index (BMI) of the subjects was measured by dividing their weight into the square of their height in meters.

\subsection{Applied Tests}

The six-station Senior Fitness Test (SFT) developed by Rikli and Jones (2001) was applied in order to determine the physical fitness levels of participants. The station constituting the test protocol included Chair Stand Test (30CST), which was performed for determining the lower extremity strengths of the subjects. The Arm Curl Test (ARCLT) measured the upper extremity strength whereas the Two Minute Step Test (2MST) was applied to determine the aerobic endurance of the subjects. Another station included the 8 Foot Up-and-Go Test (8FUAGT), which measured the dynamic balance and agility levels of the subjects. The Chair Sit and Reach Test (CSRT) was used to determine the flexibility of the hamstring muscle groups. Another station tested the upper extremity flexibility, in particular the shoulder flexibility of the subjects, was called the Back Stretch Test (BST) and constituted an integral step of the process (Rikli, Jones, 2001).

Before the SFT procedure all participants engaged in 4-5 minutes of warm-up stretching activities. The type of activities used during warm-up does not matter as long as they involve large muscle groups and they are not too strenuous (walking, jogging and stretching exercises) before the testing protocol is carried out. Before each testing the participant has to practice one or two times in order to ensure proper form.

\subsection{Statistical Analysis}

The SPSS 19.0 program for Windows was used for the statistical analysis of the data. The One-Simple Kolmogorov Smirnov test was done to determine the distribution of the data; all groups were found to have a normal distribution. The mean, standard deviation and frequency distribution of their ages, their heights and weights, their level of performing prayer, how they performed prayer, and the length of time that they had been performing prayer regularly were calculated according to the age difference between the subjects. The differences between the prayer group and sedentary group were analyzed at significance levels of 0.05 and 0.01 using the Independent Samples T-Test. 


\section{Findings}

Table 1. Some definitive features of the participants about performing prayer

\begin{tabular}{cll}
\hline \multicolumn{1}{l}{ Feature } & Number & \% \\
\hline \multicolumn{1}{c}{ Do You Perform Prayer Regularly? } & & \\
\hline Yes & 461 & 54.3 \\
No & 350 & 41.2 \\
I perform prayer on a chair & 38 & 4.5 \\
\hline For How Many Years Have You Performed Prayer? & \\
\hline More than 10 Years & 448 & 90.1 \\
From 7 to10 Years & 24 & 4.8 \\
From 4 to 6 Years & 15 & 3.0 \\
From 1to 3 Years & 6 & 1.2 \\
Less than 1 Year & 4 & 0.8
\end{tabular}

As Table 1 illustrates, it was confirmed that $54.3 \%$ of the participants performed prayer regularly five times a day; $4.5 \%$ of them performed prayer sitting on a chair, and $41.2 \%$ of them did not perform prayer at all. For those who performed prayer regularly and normally, $90.1 \%$ of the subjects reported that they had performed regular prayer for more than 10 years; $4.8 \%$ of them had performed prayer for 7 to 10 years; $3.0 \%$ of them for 4 to 6 years, and $1.2 \%$ of them for 1 to 3 years and $0.8 \%$ for less than 1 year.

Table 2. The mean and standard deviation values of the age, height, weight and BMI of the performing and non-performing participants according to their age categories

\begin{tabular}{|c|c|c|c|c|c|c|c|c|c|c|c|}
\hline \multirow{3}{*}{ Feature } & & \multicolumn{10}{|c|}{ Age Groups } \\
\hline & & \multicolumn{2}{|c|}{$\begin{array}{c}\text { Ages 60-64 } \\
\mathrm{N}=\mathbf{2 0 3}\end{array}$} & \multicolumn{2}{|c|}{$\begin{array}{l}\text { Ages 65-69 } \\
\text { N=278 }\end{array}$} & \multicolumn{2}{|c|}{$\begin{array}{c}\text { Ages } 70-74 \\
\mathbf{N}=210\end{array}$} & \multicolumn{2}{|c|}{$\begin{array}{c}\text { Ages 75-79 } \\
\mathbf{N}=107\end{array}$} & \multicolumn{2}{|c|}{$\begin{array}{c}80 \text { and above } \\
\qquad \mathrm{N}=51\end{array}$} \\
\hline & & $\begin{array}{l}\text { PPG } \\
\mathrm{n}=97\end{array}$ & $\begin{array}{l}\text { NPPG } \\
n=106\end{array}$ & $\begin{array}{c}\text { PPG } \\
n=155\end{array}$ & $\begin{array}{l}\text { NPPG } \\
n=123\end{array}$ & $\begin{array}{l}\text { PPG } \\
n=121\end{array}$ & $\begin{array}{c}\text { NPPG } \\
\mathrm{n}=89\end{array}$ & $\begin{array}{l}\text { PPG } \\
n=60\end{array}$ & $\begin{array}{c}\text { NPPG } \\
\mathrm{n}=47\end{array}$ & $\begin{array}{l}\text { PPG } \\
\mathrm{n}=28\end{array}$ & $\begin{array}{c}\text { NPPG } \\
n=23\end{array}$ \\
\hline Age ${ }_{\text {Year }}$ & $\begin{array}{c}\mathrm{X} \\
(\mathrm{SD})\end{array}$ & $\begin{array}{l}61.6 \\
(1.5)\end{array}$ & $\begin{array}{l}61.4 \\
(1.3)\end{array}$ & $\begin{array}{l}66.3 \\
(1.3)\end{array}$ & $\begin{array}{l}66.6 \\
(1.4)\end{array}$ & $\begin{array}{l}71.6 \\
(1.4)\end{array}$ & $\begin{array}{l}71.5 \\
(1.4)\end{array}$ & $\begin{array}{l}76.5 \\
(1.4)\end{array}$ & $\begin{array}{l}76.1 \\
(1.3)\end{array}$ & $\begin{array}{l}82.8 \\
(2.5)\end{array}$ & $\begin{array}{l}83.6 \\
(3.2)\end{array}$ \\
\hline Height $_{\mathrm{cm}}$ & $\begin{array}{c}\mathrm{X} \\
\mathrm{SD}\end{array}$ & $\begin{array}{l}170.4 \\
(5.4)\end{array}$ & $\begin{array}{l}170.3 \\
(5.7)\end{array}$ & $\begin{array}{l}169.3 \\
(6.4)\end{array}$ & $\begin{array}{l}170.7 \\
(6.0)\end{array}$ & $\begin{array}{l}168.1 \\
(7.0)\end{array}$ & $\begin{array}{l}169.2 \\
(6.7)\end{array}$ & $\begin{array}{l}166.9 \\
(6.5)\end{array}$ & $\begin{array}{l}169.5 \\
(6.0)\end{array}$ & $\begin{array}{l}166.0 \\
(9.0)\end{array}$ & $\begin{array}{l}167.0 \\
(6.3)\end{array}$ \\
\hline Weight $_{\mathrm{Kg}}$ & $\begin{array}{c}\mathrm{X} \\
\mathrm{SD}\end{array}$ & $\begin{array}{c}80.0 \\
(10.4)\end{array}$ & $\begin{array}{c}78.2 \\
(11.2)\end{array}$ & $\begin{array}{c}76.2 \\
(10.1)\end{array}$ & $\begin{array}{c}78.9 \\
(11.9)\end{array}$ & $\begin{array}{l}74.4 \\
(9.2)\end{array}$ & $\begin{array}{c}75.6 \\
(10.6)\end{array}$ & $\begin{array}{c}75.6 \\
(11.8)\end{array}$ & $\begin{array}{c}73.3 \\
(13.9)\end{array}$ & $\begin{array}{l}72.7 \\
(9.4)\end{array}$ & $\begin{array}{l}72.0 \\
(7.6)\end{array}$ \\
\hline $\mathrm{BMI}_{\mathrm{Kg} / \mathrm{m}}{ }^{2}$ & $\begin{array}{c}\mathrm{X} \\
\mathrm{SD}\end{array}$ & $\begin{array}{l}27.3 \\
(3.0)\end{array}$ & $\begin{array}{l}26.9 \\
(3.6)\end{array}$ & $\begin{array}{l}26.5 \\
(3.3)\end{array}$ & $\begin{array}{l}27.0 \\
(3.6)\end{array}$ & $\begin{array}{l}26.2 \\
(3.0)\end{array}$ & $\begin{array}{l}26.5 \\
(3.7)\end{array}$ & $\begin{array}{l}27.1 \\
(3.8)\end{array}$ & $\begin{array}{l}25.5 \\
(4.6)\end{array}$ & $\begin{array}{l}26.4 \\
(2.8)\end{array}$ & $\begin{array}{l}25.8 \\
(2.5)\end{array}$ \\
\hline
\end{tabular}

PPG: Prayer-performing group, NPPG: Non-prayer-performing group. X: Average, SD: Standard Deviation

The study was carried out with the voluntary participation of 849 healthy men who could conduct their daily activities independently. The mean and standard deviation values of the age, height, weight, and BMI of the performing and non-performing participants according to their age categories are given in Table 2. 
Table 3. Comparison of test performances of the performing and non-performing subjects according to their age groups

\begin{tabular}{|c|c|c|c|c|c|c|c|c|c|c|c|}
\hline \multirow{3}{*}{ TESTS } & & \multicolumn{10}{|c|}{ AGE GROUPS } \\
\hline & & \multicolumn{2}{|c|}{$\begin{array}{c}\text { Ages 60-64 } \\
N=203\end{array}$} & \multicolumn{2}{|c|}{$\begin{array}{c}\text { Ages 65-69 } \\
N=278\end{array}$} & \multicolumn{2}{|c|}{$\begin{array}{c}\text { Ages 70-74 } \\
\mathbf{N}=\mathbf{2 1 0}\end{array}$} & \multicolumn{2}{|c|}{$\begin{array}{c}\text { Ages 75-79 } \\
N=107\end{array}$} & \multicolumn{2}{|c|}{$\begin{array}{c}80 \text { and above } \\
\mathrm{N}=51\end{array}$} \\
\hline & & $\begin{array}{l}\text { PPG } \\
\mathrm{n}=97\end{array}$ & $\begin{array}{l}\text { NPPG } \\
n=106\end{array}$ & $\begin{array}{c}\text { PPG } \\
\mathrm{n}=155\end{array}$ & $\begin{array}{l}\text { NPPG } \\
n=123\end{array}$ & $\begin{array}{c}\text { PPG } \\
n=121\end{array}$ & $\begin{array}{c}\text { NPPG } \\
n=89\end{array}$ & $\begin{array}{l}\text { PPG } \\
n=60\end{array}$ & $\begin{array}{c}\text { NPPG } \\
n=47\end{array}$ & $\begin{array}{l}\text { PPG } \\
\mathrm{n}=28\end{array}$ & $\begin{array}{c}\text { NPPG } \\
n=23\end{array}$ \\
\hline \multirow{3}{*}{$\begin{array}{l}30 \text { CST } \\
\text { Chair stand test } \\
\text { (number/30sn) }\end{array}$} & $\mathrm{X}(\mathrm{SS})$ & $\begin{array}{l}16.6 \\
(2.9)\end{array}$ & $\begin{array}{l}15.6 \\
(2.8)\end{array}$ & $\begin{array}{l}16.1 \\
(2.9)\end{array}$ & $\begin{array}{l}14.7 \\
(2.5)\end{array}$ & $\begin{array}{l}14.0 \\
(2.6)\end{array}$ & $\begin{array}{l}12.7 \\
(2.7)\end{array}$ & $\begin{array}{l}13.1 \\
(2.7)\end{array}$ & $\begin{array}{l}11.5 \\
(3.0)\end{array}$ & $\begin{array}{l}12.3 \\
(3.3)\end{array}$ & $\begin{array}{l}10.0 \\
(2.8)\end{array}$ \\
\hline & $\mathrm{OF} \pm \mathrm{SS}$ & \multicolumn{2}{|c|}{$1.0 \pm 0.4$} & \multicolumn{2}{|c|}{$1.4 \pm 0.3$} & \multicolumn{2}{|c|}{$1.2 \pm 0.3$} & \multicolumn{2}{|c|}{$1.5 \pm 0.5$} & \multicolumn{2}{|c|}{$2.3 \pm 0.8$} \\
\hline & $\mathrm{t}$ & \multicolumn{2}{|c|}{$6.701 *$} & \multicolumn{2}{|c|}{$17.662 * *$} & \multicolumn{2}{|c|}{$11.610 * *$} & \multicolumn{2}{|c|}{$6.724 *$} & \multicolumn{2}{|c|}{$5.698 *$} \\
\hline \multirow{3}{*}{$\begin{array}{l}\text { ARCLT } \\
\text { Arm curl test } \\
\text { (number/30sn) }\end{array}$} & \begin{tabular}{c|}
$X$ \\
SS
\end{tabular} & $\begin{array}{l}18.2 \\
(2.7)\end{array}$ & $\begin{array}{l}17.7 \\
(2.7)\end{array}$ & $\begin{array}{l}17.7 \\
(2.2)\end{array}$ & $\begin{array}{l}16.6 \\
(2.4)\end{array}$ & $\begin{array}{l}15.5 \\
(2.5)\end{array}$ & $\begin{array}{l}14.3 \\
(2.9)\end{array}$ & $\begin{array}{l}15.2 \\
(2.5)\end{array}$ & $\begin{array}{l}13.3 \\
(2.3)\end{array}$ & $\begin{array}{l}13.9 \\
(3.3)\end{array}$ & $\begin{array}{l}12.1 \\
(2.6)\end{array}$ \\
\hline & $\mathrm{OF} \pm \mathrm{SS}$ & \multicolumn{2}{|c|}{$0.4 \pm 0.3$} & \multicolumn{2}{|c|}{$1.04 \pm 0.2$} & \multicolumn{2}{|c|}{$1.1 \pm 0.3$} & \multicolumn{2}{|c|}{$1.9 \pm 0.4$} & \multicolumn{2}{|c|}{$1.8 \pm 0.8$} \\
\hline & \begin{tabular}{l|}
$\mathrm{t}$ \\
\end{tabular} & \multicolumn{2}{|c|}{0.901} & \multicolumn{2}{|c|}{$15.238 * *$} & \multicolumn{2}{|c|}{$11.583 * *$} & \multicolumn{2}{|c|}{$15.122 * *$} & \multicolumn{2}{|c|}{3.375} \\
\hline \multirow{3}{*}{$\begin{array}{l}2 \mathrm{MST} \\
2 \text { minutes step } \\
\text { test (number } \\
\text { /2dak) }\end{array}$} & \begin{tabular}{c|}
$\mathrm{X}$ \\
$\mathrm{SS}$
\end{tabular} & $\begin{array}{c}79.8 \\
(16.4)\end{array}$ & $\begin{array}{c}74.3 \\
(15.7)\end{array}$ & $\begin{array}{c}74.8 \\
(15.0)\end{array}$ & $\begin{array}{c}66.8 \\
(14.2)\end{array}$ & $\begin{array}{c}64.8 \\
(12.2)\end{array}$ & $\begin{array}{c}59.4 \\
(13.6)\end{array}$ & $\begin{array}{c}59.3 \\
(15.2)\end{array}$ & $\begin{array}{c}46.4 \\
(14.4)\end{array}$ & $\begin{array}{c}52.0 \\
(17.4)\end{array}$ & $\begin{array}{c}42.4 \\
(13.5)\end{array}$ \\
\hline & $\mathrm{OF} \pm \mathrm{SS}$ & \multicolumn{2}{|c|}{$5.5 \pm 2.2$} & \multicolumn{2}{|c|}{$7.9 \pm 1.7$} & \multicolumn{2}{|c|}{$5.3 \pm 1.7$} & 12. & 2.9 & & \\
\hline & \begin{tabular}{l|l}
$t$ \\
\end{tabular} & 6.25 & & 18.1 & & 7.41 & & 16.6 & & & \\
\hline CSRT & $\begin{array}{c}\mathrm{X} \\
\mathrm{SS}\end{array}$ & $\begin{array}{c}1.6 \\
(5.1)\end{array}$ & $\begin{array}{l}-5.3 \\
(7.2)\end{array}$ & $\begin{array}{l}-0.1 \\
(7.0)\end{array}$ & $\begin{array}{l}-8.6 \\
(9.2)\end{array}$ & $\begin{array}{l}-3.4 \\
(7.8)\end{array}$ & $\begin{array}{l}-9.9 \\
(9.7)\end{array}$ & $\begin{array}{l}-2.9 \\
(6.5)\end{array}$ & $\begin{array}{l}-11.8 \\
(7.8)\end{array}$ & $\begin{array}{l}-4.1 \\
(9.8)\end{array}$ & $\begin{array}{l}-14.1 \\
(8.3)\end{array}$ \\
\hline Chair sit and reach & $\mathrm{OF} \pm \mathrm{SS}$ & 7.0 & & 8.4 & & $6.5=$ & 1.1 & 8.9 & & 10. & 2.5 \\
\hline & \begin{tabular}{l|l}
$\mathrm{t}$ \\
\end{tabular} & 49.5 & & 66.1 & & 26.43 & $1 * *$ & 33.1 & & 12.0 & \\
\hline BST & \begin{tabular}{c|}
$\mathrm{X}$ \\
$\mathrm{SS}$ \\
\end{tabular} & $\begin{array}{l}-6.5 \\
(8.6) \\
\end{array}$ & $\begin{array}{l}-9.7 \\
(9.0)\end{array}$ & $\begin{array}{l}-5.8 \\
(8.7) \\
\end{array}$ & $\begin{array}{l}-10.5 \\
(10.0) \\
\end{array}$ & \begin{tabular}{|l}
-9.9 \\
$(9.7)$ \\
\end{tabular} & $\begin{array}{l}-11.6 \\
(9.4)\end{array}$ & $\begin{array}{l}-11.4 \\
(9.8) \\
\end{array}$ & $\begin{array}{l}-14.3 \\
(10.1) \\
\end{array}$ & $\begin{array}{l}-14.4 \\
(9.9) \\
\end{array}$ & $\begin{array}{l}-17.7 \\
(8.6) \\
\end{array}$ \\
\hline Back scratch test & $\mathrm{OF} \pm \mathrm{SS}$ & 3.2 & & & & $1.7=$ & 1.3 & & & & \\
\hline & $\mathrm{t}$ & 6.5 & & 14.5 & & 1.4 & & 2.0 & & & \\
\hline 8FUAGT & $\begin{array}{c}X \\
\text { SS }\end{array}$ & $\begin{array}{c}4.6 \\
(0.7)\end{array}$ & $\begin{array}{c}4.8 \\
(0.7)\end{array}$ & $\begin{array}{c}4.8 \\
(0.7)\end{array}$ & $\begin{array}{c}5.4 \\
(1.0)\end{array}$ & $\begin{array}{c}5.7 \\
(1.1)\end{array}$ & $\begin{array}{c}6.4 \\
(1.2)\end{array}$ & $\begin{array}{c}6.1 \\
(1.1)\end{array}$ & $\begin{array}{c}7.3 \\
(2.2)\end{array}$ & $\begin{array}{c}7.2 \\
(1.8)\end{array}$ & $\begin{array}{c}8.5 \\
(1.5)\end{array}$ \\
\hline 8 foot up-and- go & $\mathrm{OF} \pm \mathrm{SS}$ & -0.2 & 0.1 & -0.5 & & -0.6 & $=0.1$ & -1.2 & & & \\
\hline & $\mathrm{t}$ & 9.89 & & 29.9 & & 18.85 & $7 * *$ & 13.8 & & 8.9 & \\
\hline
\end{tabular}

PPG: Prayer-performing group, NPPG: Non-prayer-performing group. X: Average, SD: Standard Deviation AD: Average Differences. $* * \mathrm{p}<0.01$, and $* \mathrm{p}<0.05$.

The average and standard deviation values of the performing and non-performing subjects' test scores according to their age groups and the significance of the differences between the groups are given in Table 3. It was determined that for the 30CST test, in which the leg strength of the subjects was measured, the prayer-performing groups' scores were higher for all age groups. According to the respective age groups, there was significant difference of 0.05 in the 60-64, 75-79 and 80+ year age groups, and a significant difference of 0.01 in the 65-69 and 70-74 year age groups, where in the prayer-performing groups' leg strength measurements were greater.

With the Arm Curl Test (ARCLT), which was designed to determine the upper extremity strength of the subjects, it was found that the prayer-performing group's scores were higher in the 65-69, 70-74, 75-79 year age groups $(\mathrm{p}<0.01)$; however, the difference was not statistically significant $(\mathrm{p}>0.05)$ in the 60- 64 and 80+ year age groups. The results of the 2MST test, which was performed to determine the aerobic endurance of the subjects, demonstrated that the prayer-performing group's scores were higher in the 60- 64, 65- 69, and 75-79 year age groups with a significance of 0.01 , and in the 70-74 and 80+ age groups with a significance of 0.05 .

For the Chair Sit and Reach Test (CSRT), which was applied to measure the lower extremity flexibility levels of the subjects, it was determined that in all age groups, the prayer-performing group had a greater level of lower extremity flexibility than the non-prayer-performing group by $\mathrm{p}<0.01$. In addition, with the Back Scratch Test (BST), which was applied to measure the upper extremity flexibility levels of the subjects, the difference was 0.05 in the 60-64 year age group and 0.01 in the 65-69 year age group; however no significant difference was found in the 70-74, 75-79 and 80+ year age groups $(\mathrm{p}>0.05)$

The results of the 8 Foot Up-and-Go Test (8FUAGT), which was applied to determine the dynamic balance coordination of the subjects, revealed scores in favor of the prayer-performing group at a level of 0.01 for all age groups (see Table 3).

\section{Discussion}

This study was carried out to determine and compare the physical fitness levels of elderly people who perform prayer with those who have a sedentary lifestyle, and to emphasize the importance of performing regular prayer for the physical fitness levels of elderly people. This research was carried out with the voluntary participation of 849 healthy 
older men who were able to independently conduct their daily activities. It was confirmed that $54.3 \%$ of the participants performed prayer regularly, five times a day; $4.5 \%$ of them performed prayer seated on a chair; and $41.2 \%$ of them did not perform prayer at all. In terms of the length of time that they had been performing daily prayers, of those participants who reported performing prayer regularly, in the prescribed manner, $90.1 \%$ had been performing prayer for more than 10 years; $4.8 \%$ had been performing prayer for 7 to 10 years; $3.0 \%$ had been performing prayer for 4 to 6 years; $1.2 \%$ of them for 1 to 3 years, and $0.8 \%$ for less than 1 year (see Table 2).

Leg strength is an important identifier in terms of older people's balance, physical performance and mobility function (Bean, Kiely, Herman, 2002); and their mobility and the ability to live independently is directly related to their physical activity and leg strength. Studies have shown that muscle strength tends to decrease by 30-50\% between the ages of 50-70. Muscle weakness and related balance and walking disorders are the most important factors related to falling in older people (Buchman et al, 2007), (Peterson et al, 2007); however, active older people show less of adecrease in muscle strength than non-active older adults.

In another study on older people, Brian et al. (2007) reported the muscle strength of a group who participated in a low-level exercise programas $11.9 \pm 3.6$ before the application and $14.7 \pm 5.5$ after the program. With a Tai-Chi exercise group, their participants had a muscle strength of $12.4 \pm 3.6$ before the application, and $13.8 \pm 4.4$ after completing the program. Furthermore, Blok et al. (2006) carried out a study with 11 male subjects with an average age of $23 \pm 5.1$.The EMG values of various muscle groups, including the neck extensors, Sternocleidomastoideus, trapezius, deltoids, biceps, triceps, rectus abdominals and erector spine muscles, were recorded while the participants were performing prayer in the bowing (rüku) and kowtow positions of prayer. The researchers concluded that the rüku and kowtow movements caused easing in the upper body and arm muscles, and that agonist and antagonist muscle movements can be a good means of exercise and develop strength (Safee et al. 2006). In addition, other researchers have suggested that numerous joints and muscles involved in physical activity during prayer may increase cerebral blood flow and postural reflex with minimal effort (Reza, Urakami, 2002).

Rikli and Jones (2001) reported ARCLT scores, which were used to determine upper extremity strength, to be $18.0 \pm 4.9$ in a high fitness level group and 10.8 \pm 3.5 in a low physical fitness group. In Toraman et al.'s study (2005), a score of $17.3 \pm 1.7$ was reported for a $60-73$ year age group before application of a training program, with a score of $22.8 \pm 3.6$ after completing the program. Similarly, in a 74-85 year age group, a score of 17.4 \pm 3.5 was obtained before the training program, and 22.1 \pm 2.6 after completion. Blok et al. (2006) reported their subjects' scores as 11.4 before participation in a training program, and 15.4 after completion; while Marzilli et al. (2004) reported the scores before a program as $20 \pm 4.4$ and afterward as $23.8 \pm 6.3$. in terms of 2 MTS scores, Yüksek (2010), conducted a study with 754 female subjects aged 60 and above and reported the scores in the 65-69, 70-74 and 75+ year age groups as higher in prayer-performing prayer subjects than non-prayer-performing subjects.

According to the results obtained in the present study, it was determined through the 30CST test, which measured the leg strength of the subjects, that the prayer-performing groups scores were higher for all ages at a level of 0.01 and 0.05 level (i.e., $\mathrm{p}<0.01$ in the 65-69 and 70-74 year age groups; and $\mathrm{p}<0.05$ in the 60-64, 74-79 and 80+ year age groups). Therefore, it can be inferred that the ritual of performing prayer, which involves 40 repetitions of rüku and 80 repetitions of bowing and standing up in kowtowover 5 daily prayer sessions, comprises a form of exercise that positively affects the leg strength of older people. Furthermore, the ARCLT scores, which measured the upper extremity strength of the participants, revealed that the prayer-performing groups' scores were higher in the 65-69, 70- 74 and 75-79 year age groups $(p<0.01)$, but that the difference was not statistically significant $(p>0.05)$ in the 60-64 and 80+ year age groups. The reason for this is thought to be the fact that there is not much activity directed toward upper extremity strength in performing prayer.

Expending energy through physical activity and cardiovascular balance tends to decrease with age; however, this decrease differs from one individual to another (McGuire \& et al, 2001). While there have been no studies concerning the energy-dissipating value of performing prayer, the movements and positions included in prayer, which involve standing up (rising), bowing (rüku), placing the head on the floor (kowtow), and saluting, repeated daily in a prescribed rhythm and array (Ibrahim, Wam Ahmad, 2008), are often compared with Yoga and Tai-Chi, which are both worth approximately 4 METs of exercise (Maughan, 2000), or 4 calories in 1 hour per kilogram of body weight (e.g., for a 70 kilo person, 70 × 4=280 cal/ hour). Studies have reported that during prayer, many joints and muscles may be involved in physical activities that improve cerebral blood flow and postural reflex with minimal effort (Reza, Urakami, 2002), and thus, performing prayer is thought to have a similar effect as the exercises involved in Tai Chi and Yoga.

In this respect, (Reza et al., Reza, Urakami, 2002) examined the angular changes and their effects related to the performance of prayer on the joints of older people with disabilities who are dependent and have difficulty in conducting daily tasks. As a result, they concluded that performing daily prayers, which can be defined as a 
low-medium volume, regular exercise, can have significant health benefits for elderly and disabled individuals. Similar effects have been found with respect to low-level exercise and Tai-Chi. For instance, Brian et al. (2007) reported the 2MST scores (performed to determine the aerobic endurance of their subjects) in a low-level exercise group as $70.1 \pm 32.3$ before a training program, and after the program as $102.9 \pm 33.8$. In a Tai-Chi exercise group, scores before the program were reported as $67.7 \pm 30.2$, and after the program as $91.2 \pm 28.5$; while in a control group, the scores before the program were reported as $61.0 \pm 29.2$, and afterward as $69.1 \pm 27.4$.

Rikli and Jones (2001) reported the 2MTS scores of a high physical fitness group as $100 \pm 24$, while a low physical fitness group yielded scores of $62 \pm 25$. Blok et al. (2006); reported the scores before a program as 36.6, and after the program 57.4, with a $56.8 \%$ improvement. Likewise, in a study conducted on female subjects aged 60 and above, Yüksek (2010) reported that the 2MTS test scores were higher with prayer-performing subjects than non-prayer-performing subjects. According to his results, the prayer-performing group's scores were found to be higher in the 60-64, 65-69 and 75-79 year age groups by 0.01 , and in the 70-74 and $80+$ age groups by 0.05 . Thus, according to these results, it may be inferred that performing ablution and the prescribed 40-rekat prayer constitutes exercise in older people and contributes to their aerobic capacity.

Aside from functional changes related to aging, structural changes may also occur, such as loss of postural stability and flexibility (Yaman, 2003). Flexibility, in particular, is a physical fitness parameter that decreases with age (Taunton \& et al, 1996). However, in Muslim societies, kneeling during prayer is a very commonly-used position; therefore, during the performance of prayer, the lower extremity joints may experience many extreme flexion movements. In this respect, Ünver et al. (2009) found that, between 50 subjects who had been performing prayer regularly for 5.7 years and 50 subjects who did not perform prayer, the prayer-performing group's thigh exterior rotation, knee extension, ankle dorsi, plantar flexion of the whole active and passive thigh and knee movement angle values were significantly higher than those of the non-prayer-performing group. Likewise Yüksek (2010), reported that, in a study with female subjects aged 60 and above, 480 of them performed prayer regularly, and 346 of them did not perform prayer. In all age groups, the lower and upper extremity test scores were higher in the prayer-performing subjects than the non-performing subjects. In a Chair Sit and Reach Test (CSRT), which was practiced in order to measure the lower extremity flexibility levels of the subjects, it was determined that in all age groups, the prayer-performing group had greater lower extremity flexibility than the non- prayer-performing group by $\mathrm{p}<0.01$. Additionally, in the Back Scratch Test (BST), which was applied to measure upper extremity flexibility, the difference was measured as 0.05 in the 60-64 year age group and 0.01 in the 65-69 year age group; however no significant difference was found in the 70-74, 75-79 and 80+ year age groups ( $p>0.05$ ). Hence, parallel to the results derived from the current study, it can be asserted that performing prayer regularly, and in particular, the movements involved in ablution, rüku and kowtow, can have positive effects on lower extremity flexibility in older people.

Another aspect of physical ability, balance, is also recognized accepted as one of the significant parameters that may decrease with age (Allison, Keller, 1997). Although the physical changes that occur with age are obvious in general, it is difficult to determine the physiological differences between two individuals aged 20 and aged 70 when they are seated. On the other hand, these physiological differences can be observed when the individuals move, react to aural prompts or move from one place to another as quickly as possible (Skelton, 2001). In this sense, the more strength that elderly people have, the shorter the time needed for them to manage activities such as climbing stairs, and the faster their reaction times become; such aspects of physical performance are closely related to quality of life (İnal, Subaş1, Munganayi, 2004). From this perspective, Rikli and Jones (2001).determined the 8 foot up-and-go test scores of elderly men with high physical level fitness as $5.1 \pm 1.2$ seconds, while the scores of a low physical fitness group averaged 8.9 \pm 2.9 seconds. Furthermore, Toraman et al. (2005), reported the 8FUAGT scores of a 60-73 year age group before a training program as $6.3 \pm 1.3$ seconds, and after the program as $4.6 \pm 0.8$ seconds. With a $74-85$ year age group, the scores before the program were 7.1 \pm 1.5 seconds, and afterward 5.02 \pm 02 seconds. In Yüksek's (2010) study with 408 female subjects who performed prayer regularly and 346 who did not perform prayer, the 8FUAGT scores were reported with the 65-69, 70-74 and75+ year age groups and in total in favor of the prayer-performing subjects. These results are supported by the current study, which confirmed that with all age groups, the prayer-performing subjects had higher scores at a level of $\mathrm{p}<0.01$ in the 8FUAGT test.

Many physical and mental problems are inevitable with age. As Yüksek and Cicioğlu (2005) contend, significant decreases in physical fitness parameters are seen as an individual ages; and such decreases in the physical fitness level of older people tend to increase with inactivity. Thus, in order to prolong an individual's ability to take care of him or herself, provide spare-time occupation, maintain musculoskeletal system integrity (including muscle strength and mass, bone mineral density and normal joint movements) and prevent coronary disease, increases in physical activity are needed (Allison \& Keller, 1997); and in this sense, any kind of exercise is better than no exercise at all (Brach \& Simonsick \& et al, 2004). 


\section{Conclusion}

In this study, $54.3 \%$ of the subjects reported performing prayer 5 times a day according to the standard ritual, while $4.5 \%$ performed prayer sitting on a chair, and $41.2 \%$ did not perform prayer at all. For all age groups, the prayer-performing group's scores in lower extremity strength and flexibility, aerobic capacity, balance and coordination were determined to be higher than those of the non-prayer-performing group. Additionally, in terms of upper extremity strength values, the 65-69, 70-74, and 75-79 year age groups' scores were higher among the prayer-performing group, while the upper extremity flexibility values of the prayer-performing group were found to be higher in the 60-64, and 65-69 year age groups. The movements involved in performing prayer, such as standing up, kneeling, kowtow, and various sitting positions, comprise a form of physical exercise; and therefore, it can be stated that the regular performance of prayer 5 times a day has a positive effect on important parameters of physical fitness such as strength, endurance, flexibility, balance and coordination positively in elderly people, thus improving their physical fitness levels and quality of life.

\section{References}

Allison, M., \& Keller, C. (1997). Physical Activity in The Elderly: Benefits and intervention strategies. The Nurse Practitioner, 22(8), 53-69. https://doi.org/10.1097/00006205-199708000-00008

Bean, J. F., Kiely, D. K., Herman, S., et al. (2002). The relationship between leg power and physical performance in mobility-limited older people, Journal of the American Geriatrics Society, 50(3), 461-467. https://doi.org/10.1046/j.1532-5415.2002.50111.x

Blok, B. M. J., Greef, M. H. G., Hacken, N. H. T., Sprenger, S. R., Postema, K., \& Wempe, J. B. (2006). The effects of a lifestyle physical activity counseling program with feedback of a pedometer during pulmonary rehabilitation in patients with COPD: A pilot study. Patient Education and Counseling, 61, 48-55. https://doi.org/10.1016/j.pec.2005.02.005

Brach, J. S., Simonsick, E. M., Kritchevsky, S., Yaffe, K., \& Newman, A. B. (2004). For the health, aging and body composition study research group the association between physical function and lifestyle activity and exercise in the health, aging and body composition study. Journal of the American Geriatrics Society, 52(4), 502-509. https://doi.org/10.1111/j.1532-5415.2004.52154.x

Brian, F., Scheinthal, S., Kemarskaya, T., \& Pruchno, R. (2007). Tai chi and low impact exercise: Effects on the physical functioning and psychological well-being of older people. Journal of Applied Gerontology, 26(5), 433-453. https://doi.org/10.1177/0733464807306915

Brown, W. J., \& Lee, C. (2004). Grandmothers on the Move: Benefits, Barriers and Best Practice Interventions for Physical Therapy in Older Women. (In) Morris M, School A. Optimizing Exercise and Physical Activity in Older People, Butterworth Heinemann, Edinburgh, 26-35. https://doi.org/10.1016/B978-0-7506-5479-1.50005-4

Buchman, A. S., Robert, S., Wilson, P. A., Boyle, A., Tang, Y., Fleischman, D. A., \& Bennett, D. A. (2007). Physical activity and leg strength predict decline in mobility performance in older persons. Journal of the American Geriatrics Society, 55(10), 1618-1623. https://doi.org/10.1111/j.1532-5415.2007.01359.x

Ibrahim, F. W. A., \& Wan, A. (2008). Study of Heart Rate Changes in Different Salats' Positions, Biomed, Proceedings $21,687-690$.

İnal, S., Subaş1, F., Munganayi, S., et al. (2003). Evaluation of the physical capacity and the quality of life of the elderly. Turkish Journal of Geriatrics, 6(3), 95-99.

Marzilli, T. S., Schuler, P. B., Willhoit, K. F., \& Stepp, M. F. (2004). Effect of a community-based strength and flexibility program on performance-based measures of physical fitness in older African-American adults. Californian Journal of Health Promotion, 2(3), 92-98.

Maughan, R. J. (2000). Nutrition in Sport, The Encyclopaedia of Sports Medicine, An IOC Medical Commission Publication, Volume: Vll, Blackwell Science Ltd,

McGuire, D. K., Levine, B. D., Williamson, J. W., et al. (2001). A 30-year follow-up of the Dallas bedrest and training study: 1. effect of age on the cardiovascular response to exercise. Circulation, 104(12), 1350-1357.

Peterson, M. J., Crowley, G. M., Sullivan, R. J., \& Morey, M. C. (2004). Physical function in sedentary and exercising older veterans as compared to national norms. J. Rehabil. Res. Dev., 41(5), 653-658. https://doi.org/10.1682/JRRD.2003.09.0141

Raci, İ. L., \& Lamia, el-F. (1997). Cultural Atlas of Islam, II.edition, İnkılab Publishing, İSTANBUL.

Rejeski, W. J., \& Brawley, L. R. (2006). Functional health: innovations in research on physical activity with older adults. Med. Sci. Sports. Exer., 38(1), 93-99. https://doi.org/10.1249/01.mss.0000183191.65316.0a 
Reza, M. F., Urakami, Y., \& Mano, Y. (2002). Evaluation of a New Physical Exercise Taken From Salat (Prayer) as a Short-Duration and Frequent Physical Activity in the Rehabilitation of Geriatric and Disabled Patients. Ann Saudi Med., 22(3-4), 177-180. https://doi.org/10.5144/0256-4947.2002.177

Rikli, R. E., \& Jones, J. C. (2001). Senior fitness test manual. Human Kinetics, Champaign, Illinois, 49-87.

Safee, M. K. M., Wan Abas, W. A. B., Abu Osman, N. A., \& Ibrahim, F. (2011). Activity of Upper Body Muscles during Bowing and Prostration Tasks in Healthy Subjects, Biomed, IPMBE Proceedings 35, pp. 125-129).

Skelton, D. A. (2001). Effects of physical activity and postural stability, Age and Aging, 30(4), 33-39. https://doi.org/10.1093/ageing/30.suppl_4.33

Taunton, J. E., Rhodes, E. C., Wolski, L. A., et al. (1996). Effect of land-based and water-based fitness programs on the cardiovascular fitness, strength and flexibility of women aged 65-75 years. Gerontology, 42(4), 204-210. https://doi.org/10.1159/000213794

Toraman, N. F., \& Ayçeman, N. (2005). Effects of six weeks of detraining on retention of functional fitness of old people after nine weeks of multicomponent training. British Journal of Sports Medicine, 39(8), 565-568. https://doi.org/10.1136/bjsm.2004.015586

Ünver, B., Karatosun, V., Gürpınar, M., \& Sağlam, L. (2009). Are regularly salat effect of the lower extremity's range of motion the joints?), XXI. Turkish Society Orthopaedics and Trauvmatology Congress-Poster Proceedings, P:075, 30, 3-8 November, İzmir.

Yaman, H. (2003). The effect of sports to the physiological function loss in the elderly. Turkish Journal of Geriatrics, 6(4), 142-146.

Y1lmaz, M. (2006). The Non-Obligatory Salats (prayers) Which Were Recommended to Perform in Certain Times and Their Sources, University Journal of Faculty of Divinity, 6(2), 63-99.

Yüksek, S, \& Cicioğlu, İ. (2005). Assessment of physical fitness level of healthy individuals aged 65-75 years. Turkish Journal of Geriatrics, 8(1), 25-33.

Yüksek, S. (2010). The effects of performing prayer on physical fitness levels of women above 60 years old, Turkish Geriatrics Society, IV. National Congress of Gerontology and geriatrics, Turkish Journal of Geriatric Congress special issue, P: 83, 1-4 April, İzmir, Turkey.

\section{Copyrights}

Copyright for this article is retained by the author(s), with first publication rights granted to the journal.

This is an open-access article distributed under the terms and conditions of the Creative Commons Attribution license which permits unrestricted use, distribution, and reproduction in any medium, provided the original work is properly cited. 